\title{
Common Sand Boa: A Vivid Herpets of Nepal
}

R.D. Chaudhary ${ }^{1}$

\section{General Introduction}

The Common Sand Boa belongs to family "Boinae", is a non-poisonous Snake, sighted first time by Author. Altogether two species of Sand Boas are recorded from Nepal. They are Johan's Sand Boa (Eryx johni) and Common Sand Boa (Eryx conicus). The former was recorded in the Eastern Development Region, mostly inside Koshitappu Wildlife Reserve, Nepal. The latter was reported from Chitawan valley, central Nepal (Shrestha, 2001).

The Common Sand Boa was sighted and photographed in 2063/02/05 B.S. near culvert of Reserve's Entrance Gate, Adhabhar, Bara. Five Sand Boas were observed throughout the month; four near the culvert of Reserve's Entrance Gate, Adhabhar and one near Motor Garage, Adhabhar.

People make generally mistake in differentiating Common Sand Boa (Eryx conicus) to Indian Rock Python (Python molurus) because of their similar coloration and, black and white body spots. To overcome this ambiguity one should always see clearly shape and size of the body, head and tail. The maximum body size of Common Sand Boa rarely exceeds 3 feet in length. It's head is relatively smaller in size than Python. Similarly, it's tail is blunt, or not sharp as seen the tail of the Python. Both Sand Boa and Python are sluggish herpetofauna.

The habitat preference by the Common Sand Boa and Python is another important clue to differentiate these two non-poisonous snakes. The Common Sand Boa mostly prefers sandy or loose-soil habitat whereas Python inhibits in moist places (Vidyarthi, 1984).

Python falls under the family "Pythoninae", is seen lying on the ground-surface but Common Sand Boa shown only it's half portion of the body outside the burrow, generally tail-part.

Both snakes are similar in dietary habits but differ in reproduction mechanism. They are carnivores and feed mainly on warm-blooded animals like mice, rats, squirrel, rabbits etc. The Common Sand Boa brings-forth young (Viviparous) but Python lays eggs (Oviparous).

\section{References:}

R. D. Vidyarthi. A Text Book of Zoology (1984). Printed at Rajendra Ravindara Printers (Pvt.) Ltd., Ram Nagar, New Delhi-110055, India.

Dr. Tej Kumar Shrestha. Herpetology of Nepal (2001). A Field Guide to Amphibians and Reptiles of Trans-Himalayan Region of Asia. Variety Printers, Kathmandu, Nepal.

' Conservation Officer, Khaptad National Park,rd_chaudhary7@yahoo.com 